\title{
Osteoarthritis Affects Health-Related Quality of Life in Korean Adults with Chronic Diseases: The Korea National Health and Nutritional Examination Surveys 2009-2013
}

\author{
Ji Hye Yang', Kiheon Lee,*, Se Young Jung', Woo Kyung Bae ${ }^{3}$, Hye Jin Ju', In Young Cho', Jae Kyeong Song', \\ Hwa Yeon Park', Jong-Soo Han ${ }^{3}$, Ga-Hye Lee', Ye Seul Bae ${ }^{1}$ \\ 'Department of Family Medicine, Seoul National University Hospital, Seoul, Korea \\ ${ }^{2}$ Department of Family Medicine, Seoul National University Bundang Hospital, Seoul National University College of Medicine, Seongnam, Korea \\ ${ }^{3}$ Department of Family Medicine, Health Promotion Center, Seoul National University Bundang Hospital, Seongnam, Korea
}

Background: Osteoarthritis (OA) is a chronic disease that commonly afflicts the elderly. This disease reduces the health-related quality of life (HRQoL) and causes a significant social burden. Whether the effect of coexisting chronic conditions on HRQoL varies according to the presence of OA remains unclear. Therefore, this study aimed to investigate this notion.

Methods: A total of 13,395 participants were identified from the 2009-2013 Korean National Health and Nutrition Examination Survey for analysis. HRQoL was assessed using the European quality of life-5 dimensions (EQ-5D) index. Patients with OA were defined as those diagnosed by a physician or those who displayed both, symptoms and radiological findings consistent with $\mathrm{OA}$ at the time of the survey. Associations between OA and 8 chronic conditions were tested using regression analysis.

Results: The EQ-5D index was lower in patients with OA than in those without (mean difference, $-0.145 ; 95 \%$ confidence interval [CI], -0.138 to $-0.151 ; \mathrm{P}<0.001$ ). Most patients with $\mathrm{OA}$ and chronic conditions showed a lower score than those without. EQ-5D was particularly lower in OA patients with hypertension, dyslipidemia, stroke, and renal failure. The estimated $\beta$ coefficient for the interaction term was significant in renal failure $(-0.034 ; 95 \% \mathrm{CI},-0.055$ to -0.012), after adjusting for demographic and socio-economic variables.

Conclusion: OA significantly affects HRQoL of Korean elderly individuals alone or when combined with other conditions. OA combined with renal failure is particularly detrimental. These results indicate the importance of managing $\mathrm{OA}$, which is an underestimated disease in public health surveys.

Keywords: Osteoarthritis; Chronic Disease; Quality of Life; Comorbidity 


\section{INTRODUCTION}

Individuals aged 65 years or older comprise $7.2 \%$ of the total population of Korea; their proportion is expected to increase to $14 \%$ by $2018 .^{1)}$ Osteoarthritis $(\mathrm{OA})$ is a common age-related chronic disease that affects $10.7 \%$ of the entire population; its prevalence increases with age, afflicting $17.1 \%, 27.3 \%, 31.5 \%$, and $34.5 \%$ of those in their $50 \mathrm{~s}, 60 \mathrm{~s}, 70 \mathrm{~s}$, and 80 s, respectively. ${ }^{2)}$

OA causes pain and physical disabilities. It has been shown to be a leading cause of long-term physical and mental health problems in the elderly, thus reducing the health-related quality of life (HRQoL) ${ }^{3-5)}$ Costs for treating OA in Korea have reached 2,142 billion won annually, significantly increasing the social burden. ${ }^{6}$ In terms of cost of medical management, $\mathrm{OA}$ is the second highest following hypertension. ${ }^{6}$ )

As a population ages, the number of patients with chronic comorbidities increases; $40 \%-56 \%$ of the Korean population aged 65 years or older was found to have chronic multimorbidities. ${ }^{7,8)}$ Such multiple chronic conditions are associated to a reduced HRQoL, including increased hospitalization, re-hospitalization, and mortality. ${ }^{9)}$ A study showed that the quality of life of OA patients decreases in most cases when accompanied by other chronic diseases; this suggests an additive relationship. ${ }^{10)}$

Treatment of OA requires continued management, as it is often not curable. However, patients with OA often do not seek appropriate treatment, as they consider pain and stiffness of the musculoskeletal system to be consequences of aging, not symptoms of a disease. ${ }^{11)}$

Studies on OA in Korea to date have mostly focused on its prevalence and risk factors. A few studies have investigated the effect of OA on the deterioration of the quality of life in patients with multimorbid chronic conditions. Therefore, this study aimed to investigate the effect of OA on HRQoL in Korean elderly individuals using data from the Korean National Health and Nutrition Examination Survey (KNHNES). The study also sought to provide evidence regarding the importance of managing $\mathrm{OA}$, which is an underestimated disease, by examining whether patients with chronic conditions experience additional adverse effects because of the presence of OA.

\section{METHODS}

\section{Subjects}

This study was exempted from review by the Institutional Review Board of Seoul National University Bundang Hospital (IRB No. X-1602333-901).

The KNHNES, conducted by the Korea Centers for Disease Control and Prevention, is a nationwide survey to collect data on health, perform medical examinations, and assess nutrition among population groups that represent the entire Korean population. This study used data from 44,085 individuals who participated in the KNHNES between 2009 and 2013.

In the KNHNES population, OA-diagnosing radiography on the hip and knee joints was performed for those 50 years or older. Therefore, subjects under 50 years of age or those who did not respond to the health interview survey were excluded from this study. A total of 13,395 participants were finally included.

\section{Variables}

\section{1) Definition of Osteoarthritis}

KNHNES defines the prevalence of OA as the presence of both pain and a Kellgren-Lawrence radiographic grade $\geq 2$ in the knee or hip joint. The Kellgren-Lawrence grading system ${ }^{12)}$ divides OA into 5 grades: 0 (none), 1 (doubtful), 2 (minimal), 3 (moderate), and 4 (severe). Grades 0 and 2 indicate a definite absence of radiographic evidence of $\mathrm{OA}$ and the presence of $\mathrm{OA}$ albeit of minimal severity, respectively. Skilled radiologists performed radiologic assessments; radiography was conducted using the DigiRAD-PG 9M (Sitec Medical Co., Kimpo, Korea) and DICOM protocols. The presence of pain was assessed by responses to the question "Have you had pain in your knee or hip joint for more than 30 days during the past 3 months?"; participants who answered "yes" were considered to have joint pain.

Patients with OA also included those who reported having been diagnosed with OA by a physician in their health interview, as well as those who were determined to have OA based on their responses to other interviews conducted for the KNHNES.

\section{2) Socio-demographic factors}

Socio-demographic variables included age, sex, smoking status, household income, education level, household type, area of residence, occupation, health insurance type, and existence of private insurance. Ages were divided into groups of 50-59, 60-69, 70-79, and 80 years or older. The areas of residence were categorized as urban and rural. Household type was classified as living alone versus living with a family. Education level was divided into middle school or lower versus high school or higher. Income level was categorized into below mediumhigh versus above medium-high based on the monthly household income. Health insurance types included regional medical insurance/ business, benefit class $1 / 2$, and none. Occupation was categorized as white collar, blue collar, and none. Smoking statuses included current smoker, past smoker, and never smoker.

\section{3) Comorbidity}

Diagnoses of asthma, depression, stroke, myocardial infarction, or ischemic heart disease were based on the responses to the KNHNES questionnaire. Asthma and depression were recorded if they afflicted the participants at the time of the interview. Stroke, myocardial infarction, and ischemic heart disease were based on historical medical diagnoses. Patients with hypertension were defined as those who were previously diagnosed by a physician or were diagnosed at the time of the examination survey. Blood pressure was measured thrice in participants' right arms in a seated position after at least 5 minutes of rest, and the final blood pressure was the average of the second and third measurements. A mercury sphygmomanometer (Baumanometer; 
Table 1. General characteristics of study participants and EQ-5D index scores according to OA prevalence and chronic health conditions

\begin{tabular}{|c|c|c|c|c|c|}
\hline \multirow{3}{*}{ Characteristic } & \multicolumn{4}{|c|}{ Weighted EQ-5D index score } & \multirow{3}{*}{ P-value } \\
\hline & \multicolumn{2}{|c|}{ Participants without $\mathrm{OA}$} & \multicolumn{2}{|c|}{ Participants with $\mathrm{OA}$} & \\
\hline & $\mathrm{N}$ & Mean \pm SD & $\mathrm{N}$ & Mean \pm SD & \\
\hline Age groups (y) & & & & & $<0.001$ \\
\hline $50-59$ & 4,486 & $0.95 \pm 0.082$ & 404 & $0.858 \pm 0.134$ & \\
\hline $60-69$ & 3,613 & $0.921 \pm 0.132$ & 823 & $0.798 \pm 0.201$ & \\
\hline $70-79$ & 2,386 & $0.879 \pm 0.188$ & 964 & $0.734 \pm 0.24$ & \\
\hline$\geq 80$ & 457 & $0.812 \pm 0.243$ & 262 & $0.697 \pm 0.257$ & \\
\hline Sex & & & & & $<0.001$ \\
\hline Men & 5,104 & $0.941 \pm 0.11$ & 484 & $0.816 \pm 0.19$ & \\
\hline Women & 5,838 & $0.909 \pm 0.14$ & 1,969 & $0.768 \pm 0.221$ & \\
\hline Household income (\%) & & & & & $<0.001$ \\
\hline$\leq 50$ & 5,961 & $0.899 \pm 0.154$ & 1,780 & $0.753 \pm 0.228$ & \\
\hline$>50$ & 4,981 & $0.953 \pm 0.085$ & 673 & $0.834 \pm 0.172$ & \\
\hline Education & & & & & $<0.001$ \\
\hline$\leq$ Middle school & 6,687 & $0.903 \pm 0.146$ & 2,173 & $0.762 \pm 0.221$ & \\
\hline ZHigh school & 4,255 & $0.957 \pm 0.082$ & 280 & $0.885 \pm 0.135$ & \\
\hline Occupation & & & & & $<0.001$ \\
\hline White collar & 2,123 & $0.961 \pm 0.066$ & 211 & $0.865 \pm 0.146$ & \\
\hline Blue collar & 3,683 & $0.942 \pm 0.097$ & 729 & $0.812 \pm 0.167$ & \\
\hline Unemployed & 5,136 & $0.891 \pm 0.166$ & 1,513 & $0.747 \pm 0.238$ & \\
\hline Insurance & & & & & $<0.001$ \\
\hline National health insurance & 10,528 & $0.929 \pm 0.12$ & 2,268 & $0.788 \pm 0.206$ & \\
\hline Medical aid & 406 & $0.808 \pm 0.207$ & 183 & $0.647 \pm 0.282$ & \\
\hline None & 8 & $0.976 \pm 0.06$ & 2 & $0.563 \pm 0.256$ & \\
\hline Private insurance & & & & & $<0.001$ \\
\hline Yes & 6,385 & $0.947 \pm 0.091$ & 896 & $0.83 \pm 0.16$ & \\
\hline No & 4,557 & $0.889 \pm 0.17$ & 1,557 & $0.743 \pm 0.241$ & \\
\hline Living status & & & & & $<0.001$ \\
\hline Alone & 1,138 & $0.872 \pm 0.187$ & 504 & $0.712 \pm 0.264$ & \\
\hline With others & 9,804 & $0.93 \pm 0.119$ & 1,949 & $0.792 \pm 0.202$ & \\
\hline Smoking status & & & & & $<0.001$ \\
\hline Never & 6,205 & $0.917 \pm 0.132$ & 1,894 & $0.776 \pm 0.215$ & \\
\hline Past & 2,607 & $0.936 \pm 0.121$ & 215 & $0.761 \pm 0.227$ & \\
\hline Current & 2,130 & $0.932 \pm 0.117$ & 344 & $0.797 \pm 0.212$ & \\
\hline Residence & & & & & $<0.001$ \\
\hline Urban & 8,105 & $0.931 \pm 0.118$ & 1,551 & $0.787 \pm 0.206$ & \\
\hline Rural & 2,873 & $0.907 \pm 0.148$ & 902 & $0.759 \pm 0.232$ & \\
\hline Hypertension & & & & & $<0.001$ \\
\hline No & 5,461 & $0.934 \pm 0.111$ & 885 & $0.792 \pm 0.217$ & \\
\hline Yes & 5,481 & $0.915 \pm 0.141$ & 1,568 & $0.769 \pm 0.214$ & \\
\hline Diabetes mellitus & & & & & $<0.001$ \\
\hline No & 8,380 & $0.933 \pm 0.114$ & 1,721 & $0.788 \pm 0.215$ & \\
\hline Yes & 2,562 & $0.898 \pm 0.156$ & 732 & $0.753 \pm 0.214$ & \\
\hline Dyslipidemia & & & & & $<0.001$ \\
\hline No & 5,287 & $0.933 \pm 0.114$ & 1,132 & $0.793 \pm 0.203$ & \\
\hline Yes & 5,655 & $0.917 \pm 0.136$ & 1,321 & $0.764 \pm 0.224$ & \\
\hline Stroke & & & & & $<0.001$ \\
\hline No & 10,551 & $0.928 \pm 0.122$ & 2,345 & $0.782 \pm 0.21$ & \\
\hline Yes & 391 & $0.83 \pm 0.205$ & 108 & $0.673 \pm 0.312$ & \\
\hline Myocardial infarction or ischemic heart disease & & & & & $<0.001$ \\
\hline No & 10,431 & $0.927 \pm 0.123$ & 2,316 & $0.779 \pm 0.214$ & \\
\hline Yes & 511 & $0.875 \pm 0.175$ & 137 & $0.742 \pm 0.235$ & \\
\hline Asthma & & & & & $<0.001$ \\
\hline No & 10,672 & $0.927 \pm 0.123$ & 2,338 & $0.781 \pm 0.212$ & \\
\hline Yes & 270 & $0.845 \pm 0.208$ & 115 & $0.703 \pm 0.264$ & \\
\hline
\end{tabular}


Table 1. Continued

\begin{tabular}{|c|c|c|c|c|c|c|}
\hline \multirow{3}{*}{ Characteristic } & \multicolumn{5}{|c|}{ Weighted EQ-5D index score } & \multirow{3}{*}{ P-value } \\
\hline & \multicolumn{2}{|c|}{ Participants without $\mathrm{OA}$} & \multicolumn{3}{|c|}{ Participants with $\mathrm{OA}$} & \\
\hline & $\mathrm{N}$ & Mean \pm SD & $\mathrm{N}$ & & Mean \pm SD & \\
\hline Renal failure & & & & & & $<0.001$ \\
\hline No & 8,602 & $0.932 \pm 0.118$ & 1,745 & & $0.794 \pm 0.202$ & \\
\hline Yes & 2,340 & $0.893 \pm 0.161$ & & 708 & $0.733 \pm 0.243$ & \\
\hline Depression & & & & & & $<0.001$ \\
\hline No & 10,595 & $0.928 \pm 0.122$ & 2,292 & & $0.785 \pm 0.209$ & \\
\hline Yes & 347 & $0.809 \pm 0.197$ & 161 & & $0.666 \pm 0.279$ & \\
\hline
\end{tabular}

All data are weighted. P-value from chi-square test for categorical variables.

EQ-5D, European quality of life-5 dimensions; OA, osteoarthritis; SD, standard deviation.

W.A. Baum Co., Copiague, NY, USA) was used in the examination. Hypertension was diagnosed if participants were taking hypertension medication, if average systolic blood pressure was $\geq 140 \mathrm{~mm} \mathrm{Hg}$, or if average diastolic blood pressure was $\geq 90 \mathrm{~mm} \mathrm{Hg}$.

Patients with diabetes were defined as those who were diagnosed by a physician during the basic examination survey. Those who were taking oral hypoglycemic agents or insulin, had a fasting blood sugar level of $126 \mathrm{mg} / \mathrm{dL}$ or greater, or had a hemoglobin Alc level of $6.5 \%$ or higher after more than 8 hours of fasting in the examination survey were also deemed to have diabetes. Patients with dyslipidemia were defined as those who were diagnosed by a physician or were taking lipid-lowering agents, had total cholesterol levels $\geq 240 \mathrm{mg} / \mathrm{dL}$, had low-density lipoprotein cholesterol levels $\geq 160 \mathrm{mg} / \mathrm{dL}$ after more than 8 hours of fasting, or whose triglyceride levels were $>200 \mathrm{mg} / \mathrm{dL}$ after more than 12 hours of fasting. Patients with renal failure were defined as those who were diagnosed by a physician during the basic examination survey or who exhibited a glomerular filtration rate $<60 \mathrm{~mL} /$ $\mathrm{min} / 1.73 \mathrm{~m}^{2}$ as calculated with the Cockroft-Gault formula using body weights and creatinine levels acquired during the examination survey.

\section{4) Assessment of health-related quality of life}

The European quality of life-5 dimensions (EQ-5D) was used for HRQoL assessment. Based on the questionnaire responses to whether any problems exist in the 5 dimensions of health (mobility, self-care, routine activities, pain/discomfort, and anxiety/depression; each scored as "no", "moderate", or "extreme"), the EQ-5D was weighed as previously reported in 2007. ${ }^{13)}$ The highest EQ-5D index score of 1 indicates a perfect health condition, whereas a lower score is interpreted as a lower quality of life. The use of the EQ-5D as an assessment tool for HRQoL in patients with OA has previously been validated. ${ }^{14)}$

\section{Data Analysis}

The raw KNHNES data were integrated and reflected by the weights suggested in the guideline for raw data analysis to project the survey participants as representative of the entire Korean population. To investigate HRQoL data according to demographic and health factors, we divided the participants according to the presence or absence of OA to obtain the mean EQ-5D index. Subsequently, a chi-square test was performed.

Linear regression analysis was conducted to determine the effect of OA combined with each of the 8 chronic diseases on HRQoL and to assess the interaction between $\mathrm{OA}$ and these chronic diseases by obtaining the $\beta$ coefficient and a 95\% confidence interval (CI). Model 1 evaluated for the interaction term between $\mathrm{OA}$ and each of the chronic conditions. Model 2 added sex and age; model 3, socio-economic factors; and model 4, the remaining factors described above. STATA ver. 14.0 (Stata Corp., College Station, TX, USA) was used for all the analyses. $\mathrm{P}<0.05$ was considered statistically significant.

\section{RESULTS}

Among the 13,395 subjects selected from a total of 16,829 KNHNES participants aged 50 years or older, 2,453 had OA. The EQ-5D index of those with $\mathrm{OA}$ (weighted mean \pm standard deviation [SD], 0.777 \pm 0.216 ) was lower than that of subjects without OA (weighted mean \pm SD, $0.925 \pm 0.126$ ). The mean difference was -0.145 with a $95 \%$ CI of -0.138 to $-0.151(\mathrm{P}<0.001)$.

No association was found between smoking or health insurance and the EQ-5D index. However, those who were older in age, female, of low household income or low education level, unemployed, living alone, without private insurance, and living in eup/myeon showed a lower EQ-5D index.

The quality of life was lower in those who had chronic conditions and OA than in those with chronic diseases only. The combination of chronic conditions and OA produced an additive relationship with respect to diabetes and depression, but a subtractive relationship with respect to cardiovascular disease and asthma. The combination of OA and 4 diseases (hypertension, dyslipidemia, stroke, and renal failure) showed a synergistic relationship with a lower-than-expected EQ-5D (Table 1).

The $\beta$ coefficient for the interaction term was significant only in renal failure and remained so after adjusting for demographic and socioeconomic variables (model 4: $\beta$ coefficient for interaction term, -0.034; $95 \%$ CI, -0.055 to -0.012 ) (Table 2, Figure 1). 
Table 2. $\beta$ Coefficient for interaction term with osteoarthritis and chronic health condition

\begin{tabular}{|c|c|c|c|c|}
\hline Variable & Model 1 & Model 2 & Model 3 & Model 4 \\
\hline \multicolumn{5}{|l|}{ Hypertension } \\
\hline No & 0 (Reference) & 0 (Reference) & 0 (Reference) & 0 (Reference) \\
\hline Yes & $-0.004(-0.026$ to 0.017$)$ & $-0.002(-0.023$ to 0.018$)$ & $-0.004(-0.024$ to 0.016$)$ & $-0.004(-0.025$ to 0.016$)$ \\
\hline \multicolumn{5}{|l|}{ Diabetes mellitus } \\
\hline No & 0 (Reference) & 0 (Reference) & 0 (Reference) & 0 (Reference) \\
\hline Yes & $0.000(-0.022$ to 0.021$)$ & $0.005(-0.016$ to 0.025$)$ & $0.002(-0.018$ to 0.021$)$ & 0.001 (-0.019 to 0.021$)$ \\
\hline \multicolumn{5}{|l|}{ Dyslipidemia } \\
\hline No & 0 (Reference) & 0 (Reference) & 0 (Reference) & 0 (Reference) \\
\hline Yes & $-0.013(-0.034$ to 0.007$)$ & $-0.010(-0.030$ to 0.009$)$ & $-0.007(-0.025$ to 0.012$)$ & $-0.007(-0.026$ to 0.011$)$ \\
\hline \multicolumn{5}{|l|}{ Stroke } \\
\hline No & 0 (Reference) & 0 (Reference) & 0 (Reference) & 0 (Reference) \\
\hline Yes & $-0.011(-0.080$ to 0.059$)$ & $-0.011(-0.079$ to 0.058$)$ & $-0.016(-0.084$ to 0.052$)$ & -0.015 (-0.083 to 0.053$)$ \\
\hline \multicolumn{5}{|c|}{ Myocardial infarction or ischemic heart disease } \\
\hline No & 0 (Reference) & 0 (Reference) & 0 (Reference) & 0 (Reference) \\
\hline Yes & $0.015(-0.024$ to 0.055$)$ & 0.016 (-0.024 to 0.056$)$ & 0.009 (-0.029 to 0.048$)$ & 0.009 (-0.031 to 0.048$)$ \\
\hline \multicolumn{5}{|l|}{ Asthma } \\
\hline No & 0 (Reference) & 0 (Reference) & 0 (Reference) & 0 (Reference) \\
\hline Yes & $0.004(-0.050$ to 0.057$)$ & $-0.016(-0.066$ to 0.034$)$ & $-0.030(-0.076$ to 0.017$)$ & $-0.029(-0.076$ to 0.017$)$ \\
\hline \multicolumn{5}{|l|}{ Renal failure } \\
\hline No & 0 (Reference) & 0 (Reference) & 0 (Reference) & 0 (Reference) \\
\hline Yes & $-0.022(-0.044$ to 0.001$)$ & $-0.026(-0.048$ to -0.004$)$ & $-0.034(-0.055$ to -0.012$)$ & $-0.034(-0.055$ to -0.012$)$ \\
\hline \multicolumn{5}{|l|}{ Depression } \\
\hline No & 0 (Reference) & 0 (Reference) & 0 (Reference) & 0 (Reference) \\
\hline Yes & $0.001(-0.050$ to 0.051$)$ & $-0.010(-0.060$ to 0.040$)$ & $-0.015(-0.062$ to 0.031$)$ & $-0.014(-0.061$ to 0.033$)$ \\
\hline
\end{tabular}

Values are presented as mean (95\% confidence interval). Model 1: simple; model 2: adjusted for age and sex; model 3: adjusted for age, sex, occupation, insurance, and private insurance; model 4: adjusted for age, sex, occupation, insurance, private insurance, living status, smoking status, and residence.

\section{DISCUSSION}

To the best of our knowledge, this study is the first to investigate the effect of OA, either independently or combined with individual chronic conditions, on the quality of life in elderly Korean individuals. We posit that patients with OA experienced decreased HRQoL owing to the fact that OA causes pain, physical disabilities, decreased mobility and function, and mental health problems. ${ }^{3-6)}$ These, in turn, were revealed in the change of the EQ-5D index. The change in HRQoL is also likely attributable to the comorbid chronic conditions; the decreased quality of life observed with chronic comorbidities mostly showed an additive or synergistic relationship, which is consistent with previous studies that assessed the effects of comorbidities in chronic conditions other than OA. ${ }^{10,15-17)}$

The common pathophysiology between renal failure and OA remains unknown. Cohen et al. ${ }^{18)}$ revealed that $69 \%$ of patients with chronic renal diseases experience pain and $55.2 \%$ of them have a sleeping disorder. Experiencing pain decreases the quality of life because of depression, disease burden, and decreased fulfillment with life. Meanwhile, sleeping disorder decreases the quality of life because of depression, disease burden, social support, and pain frequency. Decreased renal function can limit the pain control of patients with $\mathrm{OA}$, and end-stage renal disease is related to decreased HRQoL and increased length of hospital stay. ${ }^{19)}$ Renal failure combined with OA are likely to produce their synergistic effect because of the propensity of each to produce pain, physical disabilities, and decreased mobility, as well as mental health problems.

The fact that OA combined with cardiovascular disease or asthma produce a subtractive effect is likely because the relative effects of these non-OA comorbidities on the quality of life are severe. Hence, having OA does little to suppress the quality of life further. Furthermore, patients with a very low quality of life were likely to have already died or were not included in the study because of their inability to participate in the questionnaire or examination survey.

The strength of this study lies in the fact that it used data from the KNHNES, which represents the entire Korean population. It is a largescale study that includes data from 2009, when radiography for OA was first introduced in the KNHNES, to 2013, the most recent year in which data were available. However, the locations of affected joints vary; diagnosis of OA is subject to inconsistent definitions and criteria, and radiological examinations are required for clinical confirmation. ${ }^{20)}$ Controversy also exists over the identification of OA patients, ${ }^{21)}$ because many do not show any symptoms or disabilities even though they are radiologically diagnosed with $\mathrm{OA}{ }^{22)}$ Therefore, we supplemented the criteria for classifying patients with OA to include those newly deemed to have OA based on their symptoms and radiological findings in addition to relying on responses to the self-reported questionnaire for those who had previously been diagnosed with $\mathrm{OA}$.

The limitations of this study are as follows. First, the study did not include information on the severity of OA and comorbid chronic dis- 
A

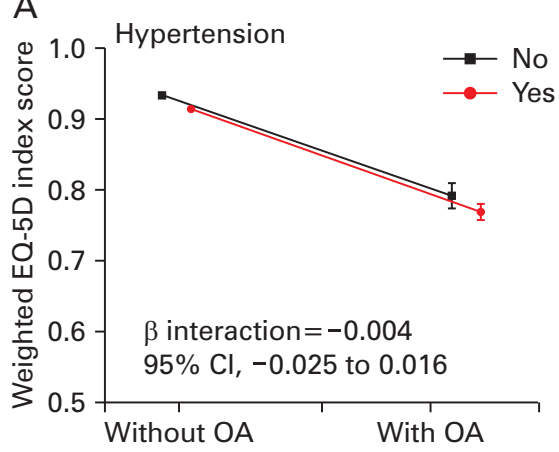

D

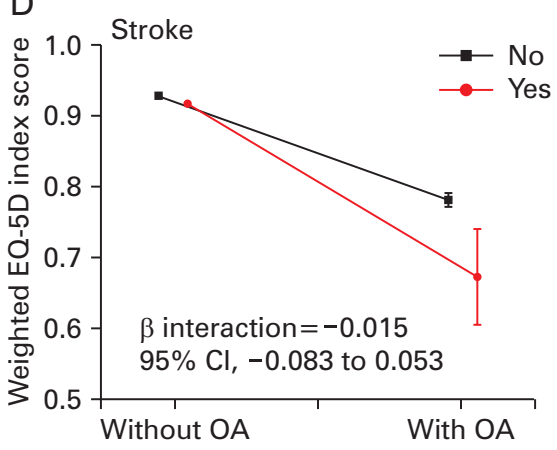

G

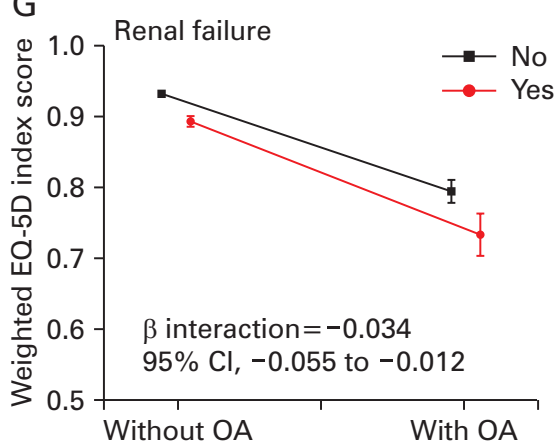

B

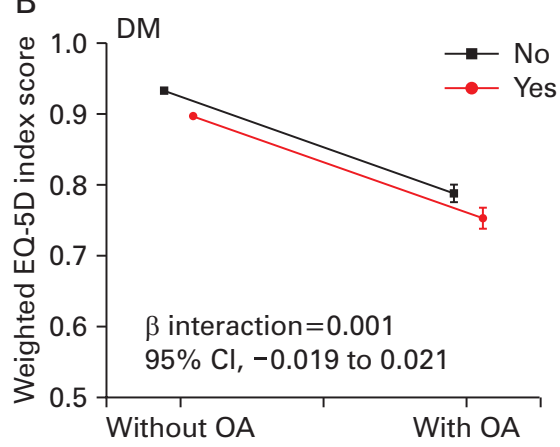

E

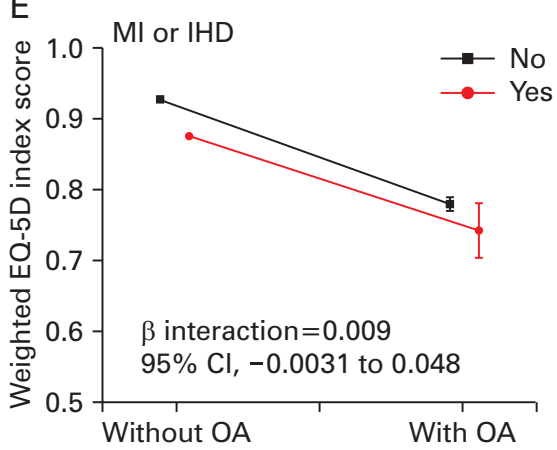

$\mathrm{H}$

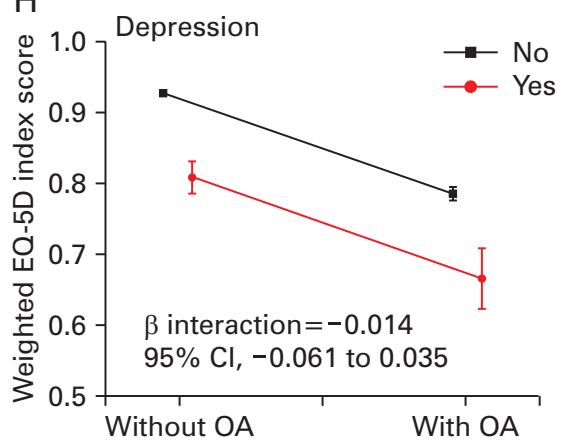

C

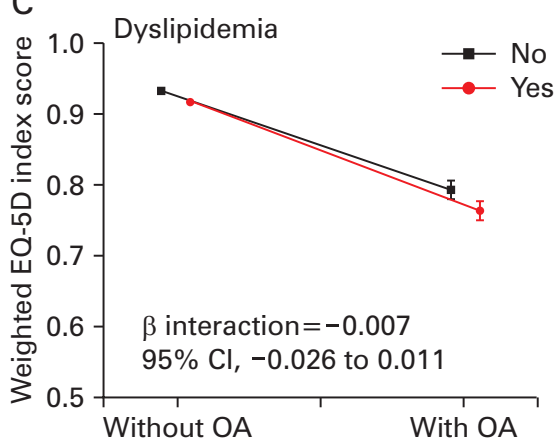

F

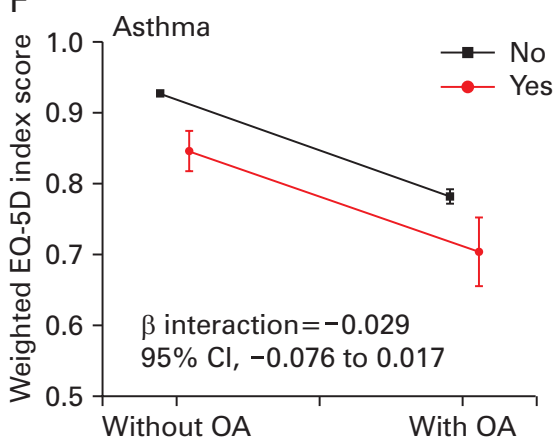

Figure 1. (A-H) Model based predictive means (95\% Cls) of osteoarthritis-stratified EQ-5D index scores for chronic health conditions. EQ-5D, European quality of life-5 dimensions; $\mathrm{Cl}$, confidence interval; DM, diabetes mellitus; Ml, myocardial infarction; IHD, ischemic heart disease; OA, osteoarthritis.

eases, or whether ailments were being treated at the time of the survey. Second, the definition of patients with OA differed in previous studies and epidemiologic surveys owing to the absence of common criteria for the diagnosis of OA (which is a fundamental problem), making it difficult to compare results. Different definitions and diagnosis criteria were employed due to the difficulties mentioned above; these may contribute to the heterogeneity of the results, including OA estimates. ${ }^{23-26)}$ Third, the data may be subject to recollection errors because identification of chronic conditions was based on questionnaire responses. Those who use health services less frequently were not likely to be diagnosed properly. Therefore, this study strictly defined each of the chronic diseases using both the results of the questionnaire combined with the results of the examination survey. Lastly, investigation on the causality between chronic conditions and decreased
HRQoL is not possible owing to the limitations of a cross-sectional study. A cohort study is required to investigate causality regarding the health of the elderly population in the future. Moreover, determining whether a combination of 3 or more diseases shows outcomes consistent with what we observed in this study is necessary.

In conclusion, we showed that OA significantly affects HRQoL and exerts a more negative effect when accompanied by other chronic conditions. In particular, the decline in HRQoL is much greater when combined with hypertension, dyslipidemia, stroke, and renal failure. The results of the present study emphasize the importance of managing OA, as patients with this disease often do not seek medical intervention. The symptoms of this disease are assumed to be due to normal aging, causing the severity and consequences of the disease to be underestimated. 


\section{CONFLICT OF INTEREST}

No potential conflict of interest relevant to this article was reported.

\section{REFERENCES}

1. Statistics Korea. 2005 Elderly population statistics [Internet]. Daejeon: Statistics Korea; 2005 [cited 2016 Aug 1]. Available from: http://kostat. go.kr/portal/korea/kor_nw/2/6 /1/index.board?bmode=read\&aSeq= 39921\&pageNo $=9$ \&rowNum $=10 \&$ amSeq $=\&$ sTarget $=\& s T x t=$.

2. Jhun HJ, Ahn K, Lee SC. Estimation of the prevalence of osteoarthritis in Korean adults based on the data from the fourth Korea national health and nutrition examination survey. Anesth Pain Med 2010;5: 201-6.

3. Cella DF, Tulsky DS. Measuring quality of life today: methodological aspects. Oncology (Williston Park) 1990;4:29-38.

4. Lee S, Kim SJ. Prevalence of knee osteoarthritis, risk factors, and quality of life: the fifth Korean National Health and Nutrition Examination Survey. Int J Rheum Dis 2017;20:809-17.

5. Parker L, Moran GM, Roberts LM, Calvert M, McCahon D. The burden of common chronic disease on health-related quality of life in an elderly community-dwelling population in the UK. Fam Pract 2014;31: 557-63.

6. Kim JD, Son MS. National health insurance statistical yearbook. Wonju: Health Insurance Review and Assessment Service, National Health Insurance Service; 2014.

7. Schram MT, Frijters D, van de Lisdonk EH, Ploemacher J, de Craen AJ, de Waal MW, et al. Setting and registry characteristics affect the prevalence and nature of multimorbidity in the elderly. J Clin Epidemiol 2008;61:1104-12.

8. Fortin M, Hudon C, Haggerty J, Akker Mv, Almirall J. Prevalence estimates of multimorbidity: a comparative study of two sources. BMC Health Serv Res 2010;10:111.

9. Fortin M, Lapointe L, Hudon C, Vanasse A, Ntetu AL, Maltais D. Multimorbidity and quality of life in primary care: a systematic review. Health Qual Life Outcomes 2004;2:51.

10. No JY, Kim SY, Kweon IS, Nam HS. Effect of arthritis and comorbid chronic conditions on health-related quality of life in Korean elderly. J Korea Acad Ind Coop Soc 2014;15:3751-8.

11. Dieppe PA, Lohmander LS. Pathogenesis and management of pain in osteoarthritis. Lancet 2005;365:965-73.

12. Kellgren JH, Lawrence JS. Radiological assessment of osteo-arthrosis. Ann Rheum Dis 1957;16:494-502.

13. Nam HS, Kim KY, Kwon SS. Research report for estimated weight for quality of life survey (EQ-5D). Cheongju: Korea Centers for Disease Control and Prevention; 2007.

14. Lim NY, Lee IO, Lee EN, Lee KS, Cho KS, Rhee SJ, et al. A validation study of EQ-5D in the patients with osteoarthritis. J Muscle Jt Health 2010;17:203-11.

15. Wee HL, Cheung YB, Li SC, Fong KY, Thumboo J. The impact of diabetes mellitus and other chronic medical conditions on health-related Quality of Life: is the whole greater than the sum of its parts? Health Qual Life Outcomes 2005;3:2.

16. Lee MH, So ES. Impact of hypertension-related comorbidity on health-related quality of life: a population-based survey in South Korea. Asia Pac J Public Health 2012;24:753-63.

17. Park SJ, Ahn S, Woo SJ, Park KH. Extent of exacerbation of chronic health conditions by visual impairment in terms of health-related quality of life. JAMA Ophthalmol 2015;133:1267-75.

18. Cohen SD, Patel SS, Khetpal P, Peterson RA, Kimmel PL. Pain, sleep disturbance, and quality of life in patients with chronic kidney disease. Clin J Am Soc Nephrol 2007;2:919-25.

19. Mujais SK, Story K, Brouillette J, Takano T, Soroka S, Franek C, et al. Health-related quality of life in CKD patients: correlates and evolution over time. Clin J Am Soc Nephrol 2009;4:1293-301.

20. Zhang W, Doherty M, Arden N, Bannwarth B, Bijlsma J, Gunther KP, et al. EULAR evidence based recommendations for the management of hip osteoarthritis: report of a task force of the EULAR Standing Committee for International Clinical Studies Including Therapeutics (ESCISIT). Ann Rheum Dis 2005;64:669-81.

21. Lawrence RC, Helmick CG, Arnett FC, Deyo RA, Felson DT, Giannini $\mathrm{EH}$, et al. Estimates of the prevalence of arthritis and selected musculoskeletal disorders in the United States. Arthritis Rheum 1998;41:77899.

22. Srikanth VK, Fryer JL, Zhai G, Winzenberg TM, Hosmer D, Jones G. A meta-analysis of sex differences prevalence, incidence and severity of osteoarthritis. Osteoarthritis Cartilage 2005;13:769-81.

23. Arden N, Nevitt MC. Osteoarthritis: epidemiology. Best Pract Res Clin Rheumatol 2006;20:3-25.

24. Duncan RC, Hay EM, Saklatvala J, Croft PR. Prevalence of radiographic osteoarthritis: it all depends on your point of view. Rheumatology (Oxford) 2006;45:757-60.

25. Felson DT, Nevitt MC. Epidemiologic studies for osteoarthritis: new versus conventional study design approaches. Rheum Dis Clin North Am 2004;30:783-97.

26. Pereira D, Peleteiro B, Araujo J, Branco J, Santos RA, Ramos E. The effect of osteoarthritis definition on prevalence and incidence estimates: a systematic review. Osteoarthritis Cartilage 2011;19:1270-85. 